\title{
Mathematical modelling of the process of quality control of construction products
}

\author{
Vadim Pogorelov ${ }^{1, *}$, Rufat Ismayil Oglu Ismayilov $^{1}$ \\ ${ }^{1}$ Don State Technical University, pl. Gagarina, 1, Rostov-on-Don, 344010, Russia
}

\begin{abstract}
The study presents the results of years of research in the field of quality management of industrial production construction production, based on mathematical modelling techniques, process and results of implementing the developed programme of monitoring and quality control in the production process of the enterprise. The aim of this work is the presentation of scientific community of the practical results of mathematical modelling in application programs. In the course of the research addressed the description of the applied mathematical models, views, practical results of its application in the applied field to assess quality control. The authors used this mathematical model in practice. The article presents the results of applying this model. The authors developed the experimental software management and quality assessment by using mathematical modeling methods. The authors continue research in this direction to improve the diagnostic systems and quality management systems based on mathematical modeling methods prognostic and diagnostic processes.
\end{abstract}

\section{Introduction}

Systematization of the quality control of construction products suggests that there should be developed some techniques of objective quality control to be systematized as a wholesome management. It is obvious that this particular step is only possible where the system includes the algorithms of determination of estimation indicators and algorithms, management, and the results of analyzing the production process. Presently, actual quality management implies financial management, because the quality of production directly effects realization, modernization, and production costs, including those unjustified losses due to optimizing the production cycle and production in view of the required standards. This article features the results of a long-term research made by the authors in the field of quality management of construction production basing on some mathematical methods of process modeling and the results of implementing the quality management program which they have developed in the production process.

\section{The historical background}

*Corresponding author: dgtu.kafedraos@yandex.ru 
Quality management has been thoroughly studied for the last 300 years in Russia and across the border, however there still remain multiple problems unsolved. Every new epoch demands new approaches and strategies, because there comes a need in transition to a new-quality technological level and more advanced ways of production and management. Rather a long distance has been covered since the first conceptual models put forward by Adam Smith [1, 142-145] and Karl Marx [2, 76-78], who assumed that there could be possible a prognostic analysis and management by means of objective models, from mathematically justified ones to those of automatic control. The works by L. B. Zelentsov, A. L. Zelentsov, K. N. Ostrovsky "Optimization model of quality management system in construction" [3], A. L. Zelentsov "Organizational mechanism of management of quality in construction in self-regulation"[4], V. V. Kostuchenko D. O., Kudinov "Informative providing of management of construction systems"[5], V. Kostuchenko, V. Pogorelov, M. Assyra "Management of Investment Strategy and Innovation in Underground Construction"[6]. S. L. Avir "Control the quality of panel construction"[7], L. I. Pokrass"Quality Management in building trust"[8], A. G. Roitman "Reliability of designs of operated buildings"[9] may serve as good examples of scientific and methodological approach to the concept of quality management by means of mathematical methods.

An important substantiation of the practical use of mathematical modeling has been stated in the conceptual monographs by Y. F. Blinov, V. Ivantsov, P. V. Serb "Methods of mathematical modeling" and "Mathematical modeling of complex subsystems" [10,11]. A significant contribution has been made by I.V.Chervjakov « Mathematical model of quality control based on the theory of interval estimation», "Competence and output quality control ", " Mathematical methods of reliability theory and quality control Methods of quality management» $[12,13,14]$ to developing the methods of estimation and product quality control by means of mathematical modeling.

Control and quality management have always been at the focus of studies; there keep coming out new publications on some complex issues relating to this multidimensional problem. The following researchers should be named here: O.A. Pobegailov «Investments in Unstable Economical System» Terra Economicus scholar V. 2-2, No 10, 2012 , PP. 35 38 [15]; O.V. Kliuchnikova, O.A. Pobegaylov «Rationalization of Strategic Management Principles as a Tool to Improve a Construction Company Services» [16]

\section{Algorithms of diagnosing and mathematical modelling of an estimation of quality}

The creation of an expedient and mathematically confirmed algorithm of estimating and revealing the defects of building production is a most critical problem to be solved by means of quality management in building production. The methods of mathematical modeling for estimating the quality of production and, consequently, the management of production are closely connected to the algorithms of diagnosing defects of technical, technological and remedial nature [11].

In terms of mathematics, production proves a certain generator of random numbers, concrete values of quality signs. The group of values, i.e. quality indicators, normally obtained in succession and in identical conditions (homogeneous raw materials, invariable regulations of technological operations, the same equipment kept in good repair, etc.) make up a batch, serving as a sample of the infinite set, generated by production with the abovementioned conditions observed. Shaped up to a certain amount of rules, the batch, being an object of economic, legal and judicial relations between the supplier and the consumer, becomes an independent carrier of quality, numerically expressed in the form of a group indicator (more often as a share of inappropriate units of production in batches or numbers of discrepancies per hundred units of production) Thus, the group indicator of quality is the 
generalized indicator that features the quality of the batch as a whole via the quality of its separate products [12]. The mathematical aspects of the model of quality assurance are directly derived from a representation of a technological process as the generator of random numbers, quality indicators. The results of quality control supply the data not only about the properties of the product, but also about the properties of the production process, including the methods of its management. The acceptance control of production loses its significance where production is absolutely controllable, analyzed and resistant to regulations and external influence [14].

Mathematical methods allow to define the boundary values of the level of discrepancies in the batch or in the technological process, broken up into stages, with the boundary values of the expected value of quality indicators at a known dispersion and bilateral restrictions. Thus, there is communication between the interval and dot estimations of the group indicator of quality - the level of discrepancies in the batch of building products or a series of technological operations.

One should well distinguish between the models of distribution of quality indicators and the model of quality assurance procedure, described within the framework of the general theory of decision-making in a state of uncertainty. To arrive at some reasonable decisions on the quality of production and efficiency of the general management of the supplier, there should be used the results of selective control under the plans developed, basing on the statistical models of distribution of quality indicators [14,15]. Thereupon, the strict mathematical form, allowing to make some corresponding estimations, shows how the reliability of the results of control decreases where the modeling representations about the distributions of indicators are simplified, e.g., owing to the substitution of hypergeometrical distribution by more simple - binomic or Puasson one.

Accordingly, basing on the principle of domination of the general theory of decisionmaking under uncertainty, one should incontestably and unequivocally define the level of trust for an interval estimation of the population mean, compatible with the risk of the final or intermediate consumer at controlling the supplier as well as the supplier's risks at controlling the consumer $[12,19]$.

Using the asymptomatic normal property of unknown dispersion, it was shown that, as well as in systems basing on dot estimation at unilateral restriction of an indicator of quality, acceptance factor $\mathrm{K}$ remains the same as in the case of a known dispersion, and the sample volume of estimated production increases $1 \frac{\mathrm{K}}{2}$ times.

For cases with the bilateral restriction of indicators of quality, the authors offer a method of constructing an area of unconditional trust for the joint distribution of the population mean and a dispersion in the form of an initial ellipse of the dispersion, the semiaxes of which in $t^{*} \lambda b$ co-ordinates only depend on sample volume $n$ and trust factor $\gamma$.

Thus, we have:

$$
\frac{t^{2}}{a_{e l}^{2}}+\frac{\left(\lambda_{b}-1\right)^{2}}{b_{e l}^{2}}
$$

where $\mathrm{a}_{e l}=\left(\frac{\gamma \kappa}{\pi}\right)^{\frac{1}{3}} *\left(\frac{n-1}{\pi 2}\right)^{\frac{1}{6}} ; b_{e l}=\left(\frac{\gamma}{\pi}\right)^{\frac{2}{3}} * \frac{1}{\kappa^{\frac{1}{3}}} *\left(\frac{2}{n-1}\right)^{\frac{1}{6}}$ - are ellipse semi-axes;

The semi-axes of a real ellipse of dispersion are linearly connected to semi-axes of the well-accepted

$$
a_{x}=\bar{x}+a_{e l} * \frac{s}{\sqrt{n}} \text { and } b_{x}=b_{e l} * s^{2}
$$

Where $\mathrm{X}$ and $\mathrm{s}^{2}$ - are selective average and dispersion respectively/ 
This particular method of constructing a confidential area is not dependable on the distribution type, as it is realized basing on the general conditions of regularity and the method of maximal credibility. Moreover, the efficiency values (interval borders) of the effectiveness function (e.g., level of discrepancies of technological processes), depending on the unknowns of the population mean and a dispersion, should be searched along the border of a real ellipse of dispersion [14].

Basing on the structural methods of reliability and the popular theorem of integrity of a chain of consistently connected elements, we have offered a method of the multiple parameter quality assurance to allow estimation of the top confidential border of the level of discrepancies of a complex product judging by the results of independent control of the elements of the object or process under study. The authors suggest that in the condition of controlling defining parameters, the top confidential border of the level of discrepancies of the ready-made object only depends on the level of trust and the minimal volume of sampling from the individual plans of control of each parameter and should be calculated using the well-known formula by Kloper-Pirson [14,20].

Practical application of the given model in the software of the automated quality monitoring systems, developed by the authors, has shown the following:

1) multiple-parameter control is essentially not a "filter - divider" of the production into fit and unfit; this type of control is expedient for being applied for estimating the level of discrepancies of a complex product or process judging by the results of controlling their constituent elements;

2) settlement value of the level of discrepancies in this method does not depend on the quantity or complexity of those individual parameters that define the quality of the "compound" product as a whole;

3) when controlling using this method, the decision-making rule has been reduced to the "fit - unfit" alternative which allows to avoid extra assumptions and also controlling the type of distribution of some individual resulting quality indicators.

Thus, a combination of the rules of decision-making under this concept with the theory of interval estimation allows:

1) to obtain a higher degree of reliability and informativeness of the results of quality assurance of building production in the relation to both finished products and also technological processes involved;

2) to simplify, in comparison with traditional monitoring systems, selection or calculation of the parameters of the target plan of control and procedure of control itself;

3 ) to provide conformity of the control methods of the TQM general ideology to the requirements of a series of ISO 9000 standards;

4) to interpret the results of control as the results of quality measurements by using these results to estimate the general management of the company.

\section{Practical application and experience of experimental work}

The authors have developed an experimental software to facilitate quality management and estimation using the methods of mathematical modeling described above.

This program for evaluating the actual operations of the building companies LLC RP Stroymekhanizatsiya - MA, LLC Palmira, JSO Assembler, JSO Sigma has allowed us to obtain and systematize a certain amount of data on the quality management of building production.

Some important results of the author's research are shown in Table 1. 
Table 1. Results of system quality assurance of building production.

\begin{tabular}{|c|c|c|c|c|c|c|c|c|}
\hline $\begin{array}{l}\text { Controllable } \\
\text { parameter } \\
\text { deviations }\end{array}$ & $\begin{array}{l}\Delta \mathrm{X}_{\mathrm{H}} \\
\left(\mathrm{X}_{\mathrm{H}}\right)\end{array}$ & $\mathrm{n}$ & $\begin{array}{c}\mathrm{K}_{\mathrm{c}}, \mathrm{K}_{\mathrm{d}}, \mathrm{K}_{\mathrm{t}}, \mathrm{C}_{\mathrm{d}}, \\
\bar{X}, \mu, \sigma, S_{c}\end{array}$ & & & & & \\
\hline $\begin{array}{l}\text { Stone (brick) } \\
\text { durability, МПа }\end{array}$ & - & 87 & 2.32 & 3.34 & 0.82 & 0.80 & 0.63 & 40 \\
\hline $\begin{array}{l}\text { Mortar durability } \\
\text { at seams, MПа }\end{array}$ & - & 125 & 5.75 & 5.04 & 0.93 & 0.89 & 0.51 & 30 \\
\hline $\begin{array}{l}\text { Concrete fabric } \\
\text { size, } \mathrm{mm}\end{array}$ & \pm 5 & 303 & -1.28 & $\begin{array}{c}10.2 \\
1 \\
\end{array}$ & 0.66 & 0.55 & 0.44 & 20 \\
\hline $\begin{array}{l}\text { Concrete fabric } \\
\text { spacing, rows }\end{array}$ & - & 225 & 1.80 & 1.89 & 0.36 & 0.24 & 0.33 & 90 \\
\hline $\begin{array}{l}\text { Horizontal seam } \\
\text { thickness, mm }\end{array}$ & $\begin{array}{l}-2 \\
+3 \\
\end{array}$ & 380 & 3.41 & 5.48 & 0.62 & 0.47 & 0.44 & 48 \\
\hline $\begin{array}{l}\text { Wall element } \\
\text { thickness, mm }\end{array}$ & \pm 15 & 326 & 5.85 & 8.80 & 0.88 & 0.84 & 1.38 & 10 \\
\hline $\begin{array}{l}\text { Wall axial } \\
\text { deviation, } \mathrm{mm}\end{array}$ & \pm 10 & 292 & -0.28 & 5.63 & 0.95 & 0.88 & 2.12 & 20 \\
\hline $\begin{array}{l}\text { Wall vertical } \\
\text { deviation, } \mathrm{mm}\end{array}$ & 10 & 300 & $6.83 / 1.5$ & $\begin{array}{l}6.03 \\
/ 0.9 \\
\end{array}$ & $\begin{array}{l}0.83 \\
10.8 \\
\end{array}$ & $\begin{array}{l}0.7 / \\
0.8 \\
\end{array}$ & $\begin{array}{l}0.32 \\
10.9 \\
\end{array}$ & 20 \\
\hline $\begin{array}{l}\text { Deviation of } \\
\text { marks of support, } \\
\mathrm{mm}\end{array}$ & -10 & 446 & -2.10 & 6.23 & 0.65 & 0.53 & 1.09 & 5 \\
\hline $\begin{array}{l}\text { Opening width, } \\
\text { mm }\end{array}$ & +15 & 304 & 7.97 & $\begin{array}{c}10.7 \\
6 \\
\end{array}$ & 0.76 & 0.63 & 0.90 & 5 \\
\hline
\end{tabular}

$\Delta \mathrm{XH}_{\mathrm{H}}$ - standard tolerance, $\mathrm{n}$ - sampling size. - average index. - standard deviations of parameters. Ks - conformity to norm factor. Kd - absence-of-defects. KT - parameter of technological process accuracy. Sd - criticality defect parameter. In the denominator, the values of longonormal distributions with parameters are shown

Thus, the largest deviations revealed are in the parameters of the thickness of mortar seams, reinforcing, and also some geometrical parameters of masonwork. Judging by the value of Cd parameter of criticality, the defects of brick durability, laying of horizontal seams and reinforcing should be treated as critical defects, while other deviations as less significant ones.

The importance of critical defects calls for their quantitative analysis in order to reveal whatever causes of such deviations, specifically defects in concrete fabric and horizontal seams. The results of monitoring the group parameters of quality (average for all the objects), are presented in Table 2 .

Table 2. Values of group parameters of quality.

\begin{tabular}{|l|c|c|c|}
\hline Quality parameter group & $\mathrm{K}_{\mathrm{s}}$ & $\mathrm{K}_{\mathrm{d}}$ & $\mathrm{K}_{\mathrm{t}}$ \\
\hline Material indicators & 0.69 & 0.62 & 0.48 \\
\hline Geometrical indicators & 0.81 & 0.70 & 1.16 \\
\hline Indicators of bonding elements & 0.72 & 0.61 & 0.12 \\
\hline Indicators of of seams & 0.61 & 0.52 & 0.58 \\
\hline Non-critical geometrical indicators & 0.82 & 0.77 & 0.96 \\
\hline
\end{tabular}




\section{Conclusions}

The independent quality control, basing on some traditional methods of inspection and using the methods of mathematical modeling of the program developed by the authors has shown an insignificant partial discrepancy in the results of estimation which has confirmed both the efficiency of the product and the appropriateness of the concept of mathematical modeling. The authors continue their research in this direction for the purposes of refining both diagnostic systems and quality control systems basing on the mathematical methods of modeling prognostic and diagnostic processes.

\section{References}

1. A. Smith, Eksmo,960(2007)

2. K. Marx, CIT42, 41-174 (1989)

3. L. Zelentsov, A. Zelentsov, K. Ostrovsky, Scientific review11, 221-224 (2013)

4. A. Zelentsov, Cand. Sciences., 140 (2013)

5. V. Kostuchenko,D. Kudinov, Engineering journal of don, 3 (2012)

6. V.Kostuchenko, V. Pogorelov, M. Assyra, Procedia Engineering165, 965-971(2017)

7. S. Avir,Control the quality of panel construction(M.: Stroyizdat, Moscow, 1989)

8. L. Pokrass, Quality Management in building trust (Budivelnik,Kiev,1976)

9. A. Roitman, Reliability of designs of operated buildings (M. : Stroyizdat, Moscow, 1985)

10. Y. Blinov, V. Ivantsov, P. Serb,Methods of mathematical modeling(TRTU,Taganrog, 2012)

11. Y. Blinov, V. Ivantsov, P. Serb,Mathematical modeling of complex subsystems (Yufu, Taganrog, 2014)

12. I.Chervjakov, Mat. Sciences, 141 (2005)

13. I.Chervjakov, Methods of quality management8, 38-41 (2004)

14. I.Chervjakov, Methods of quality management5, 37-43 (2005)

15. O. Pobegailov, Terra Economicus 10, 35-38 (2012).

16. O.Kliuchnikova, A. Pobegaylov, Procedia Engineering 150, 2168 - 2172 (2016)

17. A.Subetto, Methods projects and works, 128 (1982)

18. M. Tikhomirov, Industrial and civil construction 10, 47-50(2011)

19. S. John S. Oakland, M. Marosszeky, Routledge, 236(2012)

20. S. Orudshev,Dialectics as a Group. To Verhealtnis of dialectics, logic and theory of knowledge. (VEB Deutscher Verlag of Sciences, Berlin, 1979). 